\title{
Dual Use of E-Cigarettes with Conventional Tobacco is Associated with Increased Sleep Latency
}

Laura Crotty Alexander ( $\square$ lcrotty@ucsd.edu )

VA San Diego Healthcare System

Ira Advani

VA San Diego Healthcare System

Deepti Gunge

VA San Diego Healthcare System

Shreyes Boddu

University of California, San Diego

\section{Sagar Mehta}

University of California, San Diego

Kenneth Park

VA San Diego Healthcare System

\section{Samantha Perera}

University of California, San Diego Josephine Pham

VA San Diego Healthcare System

Sedtavut Nilaad

University of California, San Diego

Jarod Olay

VA San Diego Healthcare System

Lauren Ma

University of California, San Diego

Jorge Masso-Silva

VA San Diego Healthcare System

Xiaoying Sun

University of California, San Diego

Sonia Jain

University of California, San Diego

Atul Malhotra

University of California, San Diego 
Keywords: vaping, electronic cigarettes, sleep latency, marijuana, cocaine

Posted Date: June 16th, 2021

DOI: https://doi.org/10.21203/rs.3.rs-567925/v1

License: (c) (i) This work is licensed under a Creative Commons Attribution 4.0 International License. Read Full License 


\section{Abstract}

Rationale

Health effects of e-cigarettes remain relatively unknown, including impact on sleep quality. We previously showed in a pilot study that females who both smoke conventional tobacco and vape e-cigarettes (dual users) had decreased sleep quality and more difficulty falling asleep, suggesting an effect of gender. We undertook this study in a larger cohort to assess the impact of e-cigarette, conventional tobacco, and dual use on sleep quality, cough, and drug use.

\section{Methods}

Participants $(n=1198)$ were recruited through online surveys posted to social media sites with a monetary incentive. Participants were grouped by inhalant use, with $8 \%$ e-cigarette users, $12 \%$ conventional tobacco users, $30 \%$ dual users, and $51 \%$ non-smokers/non-vapers.

Results

Dual use of e-cigarettes and conventional tobacco was associated with increased sleep latency relative to non-smokers/non-vapers $(p=0.012)$. Dual use was also associated with a higher reporting of cough $(p=$ $0.034)$, as well as increased marijuana $(p<0.001)$ and cocaine usage $(p<0.001)$.

\section{Discussion}

Dual use is associated with longer sleep latency, suggesting that the shared component nicotine may be a driver. Because sleep broadly impacts multiple aspects of human health, defining the effects of ecigarettes and vaping devices on sleep is critical to further our understanding of the effects of vaping on health.

\section{Introduction}

The popularity of electronic cigarette (e-cigarette) and vaping devices such as JUUL have spiked in the last few years especially amongst adolescents and young adults $(1,2)$. Despite major increases in ecigarette usage, there is a lack of data on potential health effects of these devices (3-5). The e-cigarette or vaping device use-associated lung injury (EVALI) epidemic that started in 2019 illuminated the dangers of inhaling chemicals contained within these vaping aerosols (6). Users of inhaled cannabinoids and nicotine generated from electronic devices who developed EVALI ranged from short-term (weeks) to longterm (years) users of these e-devices (7). Due to the immediate impact of active agents, such as nicotine and marijuana, encompassed in the aerosols on activating pathways of the central nervous system (CNS), it is likely that inhalation of aerosols from e-devices will impact sleep.

We previously completed a small pilot study (274 subjects) which determined that women who both smoked conventional tobacco products as well as vaped e-cigarettes (dual users) had a significant 
decrease in their sleep quality (8). Since dual users may intake greater quantities of nicotine than sole users of conventional tobacco or e-cigarettes, we hypothesized that nicotine may be the underlying culprit in these findings of diminished sleep quality. Adult users of e-cigarettes most commonly use them alongside of conventional tobacco cigarettes, such that this is a key population to study. Women are known to have different susceptibilities to the effects of tobacco (9), and may have higher susceptibility to the sleep disrupting effects of nicotine in particular. We undertook the current study, utilizing our established UCSD Inhalant Questionnaire (updated every 6-12 months to accurately assess use of new e-devices, inhalants and vaping methods) $(8,10)$, to recruit a larger cohort powered to evaluate the effects of e-cigarettes, conventional tobacco, and dual usage on sleep quality in the context of gender and age, via use of the Pittsburgh Sleep Quality Index (PSQI) (11).

Use of e-cigarettes has been associated with increased cough (12-14). In our prior study, we saw a nonsignificant trend of increased cough in e-cigarette vapers versus non-smoking/non-vaping controls (15). With this larger study, we sought to assess the prevalence of cough in different types of inhalant users, with a specific question regarding whether dual use leads to the highest rates of cough across inhalant users. Further, we sought to assess the impact of cough on sleep disruption, and severity of cough via use of the Leicester Cough Questionnaire (LCQ) (16).

We conducted this social media platform-based, reward-incentivized, anonymous research survey to determine whether dual users have worsened sleep quality due to high intake of nicotine leading to longer sleep latency and increased cough. While vaping has been identified as a gateway to conventional tobacco, it is unknown whether use of e-cigarettes is associated with use of other drugs, such as marijuana and cocaine. Thus, we undertook these studies to assess for concomitant use of non-nicotine drugs with tobacco and e-cigarette use $(17,18)$.

\section{Methods}

\section{Participants}

Participants were recruited to participate in online surveys through wide-spread Twitter, Facebook, Craigslist and Reddit advertisements. All studies were carried out in accordance with national human subjects research guidelines, with all subjects providing informed consent. All protocols were approved by the University of California, San Diego (UCSD) institutional review board (IRB protocol \# 160204). Participants were incentivized to complete online surveys through random lottery. IP addresses were recorded to identify participant's location as well as prevent multiple responses per device.

\section{Materials}

Inhalant use patterns, sleep quality, and cough were assessed utilizing the UCSD Inhalant Survey $(8,10)$, the Pittsburgh Sleep Quality Index (PSQI), and the Leicester Cough Questionnaire (LCQ) $(10,15)$. All three surveys plus demographic questions and those to quantify marijuana and other recreational drug use were combined in one online survey. 


\section{Analysis}

Descriptive analyses were performed to summarize the data by inhalant use groups. Group comparisons used analysis of variance (ANOVA) tests for the continuous variables and Chi-square tests for the categorical variables. A multivariable linear regression model was performed to study the association of inhalant use group with sleep quality, adjusting for age and gender. Mean differences (and $95 \% \mathrm{Cl}$ ) in PSQI scores were estimated for e-cigarette users vs non-smokers, dual users vs nonsmokers, dual users vs e-cigarette only users, dual users vs conventional cigarette users, and conventional cigarette users vs non-smokers. We also assessed whether the effect of inhalant groups on sleep quality differed between males and females by including an interaction term between gender and inhalant groups in the model. A similar analysis was conducted for the other continuous outcomes. A logistic regression model was performed to study the association of inhalant use group with reporting presence of cough in the past 30days, adjusting for age and gender. OR (and $95 \% \mathrm{Cl}$ ) were estimated for all pairwise inhalant group comparisons. P-values for pairwise group comparisons were adjusted using the method of Benjamini \& Hochberg (1995) (19). Statistical software R (version 3.6.1) was used for the analysis (http://www.rproject.org).

\section{Results}

\section{Demographics of Survey Participants}

We received responses to surveys from 1198 individuals, of which 933 included complete data (Fig. 1). Mapping of survey response IP addresses demonstrated the international reach obtained by the social media advertisements utilized, with responses from 47 countries across 6 continents (Fig. 2). Reported ages of participants ranged from 13 to 70 years, with a mean of 26 years. Gender distribution was fairly even with $53 \%$ identifying as female, $46 \%$ as male, and $1 \%$ as non-binary or who refused to answer. The majority of respondents were Caucasian (62\%), with the next highest percent being Asian (19\%) and Asian Indian (6\%; Table 1). 
Table 1

Demographics of Survey Responders

\begin{tabular}{|c|c|c|c|c|c|c|}
\hline & Nonsmoker & Conventional & $\begin{array}{l}\text { E-cig } \\
\text { User }\end{array}$ & Dual User & Overall & \multirow[t]{2}{*}{$\begin{array}{l}p \\
\text { value }\end{array}$} \\
\hline & $n=472$ & $n=109$ & $n=74$ & $n=278$ & $n=933$ & \\
\hline \multicolumn{6}{|l|}{ Age } & \multirow{2}{*}{ ¿. } \\
\hline Mean (SD) & $22.6(12.1)$ & $34.6(11.8)$ & 18.4 (3.9) & $30.6(11.9)$ & $\begin{array}{l}26.1 \\
(12.6)\end{array}$ & \\
\hline \multicolumn{7}{|l|}{ Gender } \\
\hline Female & $\begin{array}{l}265 \\
(56.14 \%)\end{array}$ & $70(64.22 \%)$ & $\begin{array}{l}49 \\
(66.22 \%)\end{array}$ & $112(40.29 \%)$ & $\begin{array}{l}496 \\
(53.16 \%)\end{array}$ & \multirow[t]{4}{*}{$<.001$} \\
\hline Male & $200(42.37 \%)$ & 39 (35.78\%) & $\begin{array}{l}24 \\
(32.43 \%)\end{array}$ & $163(58.63)$ & $\begin{array}{l}426 \\
(45.66 \%)\end{array}$ & \\
\hline Other & $7(1.48 \%)$ & $0(0 \%)$ & $1(1.35 \%)$ & $3(1.08 \%)$ & $\begin{array}{l}11 \\
(1.18 \%)\end{array}$ & \\
\hline Total & $\begin{array}{l}472 \\
(99.99 \%)\end{array}$ & $109(100 \%)$ & $\begin{array}{l}74 \\
(100 \%)\end{array}$ & $278(100 \%)$ & $\begin{array}{l}933 \\
(100 \%)\end{array}$ & \\
\hline \multicolumn{7}{|l|}{ Ethnicity } \\
\hline Alaska Native & $1(0.21 \%)$ & $2(1.85 \%)$ & $0(0 \%)$ & $0(0 \%)$ & $\begin{array}{l}3 \\
(0.32 \%)\end{array}$ & \\
\hline Asian Indian & $18(3.84 \%)$ & $9(8.33 \%)$ & $\begin{array}{l}9 \\
(12.16 \%)\end{array}$ & $17(6.14 \%)$ & $\begin{array}{l}53 \\
(5.71 \%)\end{array}$ & \\
\hline Asian & $\begin{array}{l}123 \\
(26.23 \%)\end{array}$ & $8(7.41 \%)$ & $\begin{array}{l}14 \\
(18.92 \%)\end{array}$ & $27(9.75 \%)$ & $\begin{array}{l}172 \\
(18.53 \%)\end{array}$ & $\begin{array}{c}<.001 \\
0.00\end{array}$ \\
\hline African American & $7(1.49 \%)$ & $3(2.78 \%)$ & $0(0 \%)$ & $5(1.81 \%)$ & $\begin{array}{l}15 \\
(1.62 \%)\end{array}$ & \\
\hline Pacific Islander & $4(0.85 \%)$ & $0(0 \%)$ & $1(1.35 \%)$ & $1(0.36 \%)$ & $\begin{array}{l}6 \\
(0.65 \%)\end{array}$ & \\
\hline White & $\begin{array}{l}260 \\
(55.44 \%)\end{array}$ & $80(74.07 \%)$ & $37(50 \%)$ & 202 72.92\%) & $\begin{array}{l}579 \\
(62.39 \%)\end{array}$ & \\
\hline Middle Eastern & $0(0 \%)$ & $0(0 \%)$ & $0(0 \%)$ & $2(0.72 \%)$ & $\begin{array}{l}2 \\
(0.22 \%)\end{array}$ & \\
\hline \multicolumn{7}{|c|}{$\begin{array}{l}\text { *Comparisons among the } 4 \text { groups are all significant with } p<0.001 \text {. ANOVA test was used for age; } \\
\text { and Chi-square test was used for gender and ethnicity. **Multivariable analysis on ethnicity and race } \\
\text { was condensed to } 3 \text { groups }- \text { Asian, White (non-Hispanic), and Other (Mixed, Prefer not to Answer, } \\
\text { American Indian, Pacific Islander, and Black (non-Hispanic). }\end{array}$} \\
\hline
\end{tabular}




\begin{tabular}{|lccccl|}
\hline Hispanic & $7(1.49 \%)$ & $0(0 \%)$ & $2(2.7 \%)$ & $4(1.44 \%)$ & $\begin{array}{l}13 \\
(1.4 \%)\end{array}$ \\
\hline Mixed & $38(8.1 \%)$ & $6(5.56 \%)$ & $\begin{array}{l}10 \\
(13.51 \%)\end{array}$ & $15(5.42 \%)$ & $\begin{array}{l}69 \\
(7.44 \%)\end{array}$ \\
\hline $\begin{array}{l}\text { Prefer Not To } \\
\text { Answer }\end{array}$ & $11(2.35 \%)$ & $0(0 \%)$ & $1(1.35 \%)$ & $4(1.44 \%)$ & 16 \\
\hline Total & $469(100 \%)$ & $108(100 \%)$ & $74.72 \%)$ \\
\hline
\end{tabular}

The overall cohort was divided into four inhalant groups: non-smokers/non-vapers (51\%), conventional tobacco smokers (12\%), e-cigarette users (8\%), and dual users of e-cigarettes and conventional tobacco $(30 \%$; Table 1). This again highlights the fact that many adults in the general population use both ecigarette and conventional tobacco. There were significant differences in age across inhalant groups $(p<$ 0.001 ). Conventional tobacco users had the highest mean age (35 years, $S D=11.8$ ), while e-cigarette users had the lowest mean age (18 years, $S D=3.9$; Table 1). For dual users, the percentage of Caucasian respondents was highest at $73 \%$, followed by Asian at $10 \%$, and Asian Indian at $6 \%$. E-cigarette users had a lower percentage of Caucasian respondents (50\%) and higher mixed race at $14 \%$. The racial ethnicity self-identification in the conventional tobacco user group was similar to dual users; however, nonsmokers/ non-vapers had a lower percentage of Caucasian respondents $(55 \%)$ and a higher percentage of Asian respondents (26\%). There was a low response rate of Alaska Native, Pacific Islander, Middle Eastern, Hispanic, African American and mixed ethnicities.

\section{Presence of Cough is Associated with Poorer Sleep Quality and Dual Inhalant Use}

Analysis of PSQI scores by presence of cough revealed that subjects with a cough had higher PSQI scores $(7.64, S D=3.661)$, indicating worsened sleep quality, compared to those without a cough $(6.88$, $S D=3.648 ; p=0.002)$. These data suggest that cough may have a direct adverse impact on sleep quality in this cohort. However, we didn't find a significant association between the inhalant groups and PSQI scores (Table 2). There was also no evidence of interaction between inhalant groups and gender on PSQI scores $(p=0.89)$. When gender was assessed as a variable, males were found to have lower PSQI scores (better sleep quality) relative to females (mean difference of $-0.87,95 \% \mathrm{Cl}:-1.36$ to $-0.39, p<0.001$ ). 
Table 2

Linear Regression Model to assess the association between inhalant groups and PSQI scores

\begin{tabular}{|c|c|c|c|c|}
\hline Pairwise Group Comparisons & Mean Difference & $95 \% \mathrm{Cl}$ & $\begin{array}{l}\text { Raw } \\
\text { p-value }\end{array}$ & $\begin{array}{l}\text { Adjusted } \\
\text { p-value }\end{array}$ \\
\hline Dual vs Nonsmoker & 0.30 & $(-0.28,0.88)$ & 0.314 & 0.471 \\
\hline Dual vs E-cig & 0.07 & $(-0.92,1.06)$ & 0.888 & 0.888 \\
\hline Dual vs Conventional & 0.81 & $(-0.19,1.65)$ & 0.056 & 0.336 \\
\hline E-cig vs Nonsmoker & 0.23 & $(-0.69,1.41)$ & 0.627 & 0.752 \\
\hline E-cig vs Conventional & 0.74 & $(-0.40,1.41)$ & 0.203 & 0.428 \\
\hline Conventional vs Nonsmoker & -0.52 & $(-1.33,1.89)$ & 0.214 & 0.428 \\
\hline \multicolumn{5}{|c|}{$\begin{array}{l}\text { Model adjusted for age (mean difference }=0.001 \text { per year increase, } 95 \% \mathrm{Cl}:(-0.02,0.02), p=0.95) \text {, } \\
\text { gender (Male vs Female mean difference }=-0.87,95 \% \text { Cl: }(-1.36,-0.39), p<0.001), \text { Race }(\text { Asian vs White } \\
\text { mean difference }=-0.03(-0.63,0.58) ; \text { Other vs White mean difference }=0.31(-0.46,1.09) ; p=0.703) \text {, } \\
\text { and Ethnicity (Hispanic vs Non-Hispanic mean difference }=-0.690(-1.51,0.13) ; \text { Unknown vs Non- } \\
\text { Hispanic mean difference }=-0.92(-2.53,0.69), p=0.16) \text {. }\end{array}$} \\
\hline
\end{tabular}

Inhalant use was associated with higher reporting of cough. Dual users had the highest reporting of cough in the last 30 days (48\%), with e-cigarette users having the lowest reporting of cough of all inhalant users (24\%). Logistic regression model adjusting for age and gender showed dual users had a higher presence of cough compared to non-smokers/non-vapers ( $\mathrm{OR}=1.50,95 \% \mathrm{Cl}: 1.09$ to 2.07, raw $\mathrm{p}=0.012$, adjusted $p=0.034)$ and e-cigarette users $(\mathrm{OR}=3.00,95 \% \mathrm{Cl}: 1.64$ to 5.48 , raw and adjusted $p<0.001)$. Ecigarette users reported a lower presence of cough than non-smokers/ non-vapers (OR $=0.50,95 \% \mathrm{Cl}$ : 0.29 to 0.89 , raw $p=0.017$, adjusted $p=0.034$ ) (Table 4 ). There is no interaction between gender and inhalant groups on reported incidence of cough $(p=0.85)$.

\section{Dual Use and Female Gender are Associated with Longer Sleep Latency}

Sleep latency was associated with inhalant type, with dual users having longer sleep latency compared to non-smoking/non-vaping subjects (mean difference of $4.7 ; 95 \% \mathrm{Cl}: 1.75$ to 7.65 , raw $p=0.002$, adjusted $p$ $=0.012$ ) (Table 3). Gender was also independently associated with sleep latency, with males having shorter sleep latency compared to females (mean difference of $-2.86,95 \% \mathrm{Cl}:-5.35$ to $-0.37, \mathrm{p}=0.024$ ), such that males in this cohort were found to fall asleep faster than females. There was no significant interaction effect between gender and inhalant groups on sleep latency $(p=0.41)$, with both male and female dual users reporting longer sleep latency (4.25 minutes longer relative to non-smoking/non-vaping subjects for males, and 4.82 minutes for females). 
Table 3

Linear Regression Model to assess the association between inhalant groups and sleep latency

\begin{tabular}{|c|c|c|c|c|}
\hline Pairwise Group Comparisons & Mean Difference & $95 \% \mathrm{Cl}$ & $\begin{array}{l}\text { Raw } \\
\text { p-value }\end{array}$ & $\begin{array}{l}\text { Adjusted } \\
\text { p-value }\end{array}$ \\
\hline Dual vs Nonsmoker & 4.10 & $(1.14,7.06)$ & 0.007 & 0.042 \\
\hline Dual vs E-cig & 4.73 & $(-0.31,9.78)$ & 0.066 & 0.194 \\
\hline Dual vs Conventional & 3.67 & $(-0.67,8.01)$ & 0.097 & 0.194 \\
\hline E-cig vs Nonsmoker & -0.63 & $(-5.29,4.02)$ & 0.789 & 0.843 \\
\hline E-cig vs Conventional & -1.06 & $(-6.96,4.84)$ & 0.724 & 0.843 \\
\hline Conventional vs Nonsmoker & 0.43 & $(-3.82,4.68)$ & 0.843 & 0.843 \\
\hline \multicolumn{5}{|c|}{$\begin{array}{l}\text { Model adjusted for age (mean difference }=0.04 \text { per year increase, } 95 \% \mathrm{Cl}:(-0.07,0.15), p=0.522) \text { and } \\
\text { gender (Male vs Female mean difference }=-2.88,95 \% \mathrm{Cl}:(-5.36,-0.39), p=0.023), \text { Race }(\text { Asian vs White } \\
\text { mean difference }=-3.83(-6.93,-0.74) ; \text { Other vs White mean difference }=-0.13(-4.08,3.83), p=0.05) \text {, anc } \\
\text { Ethnicity (Hispanic vs Non-Hispanic mean difference }=-4.38(-8.27,-0.12) ; \text { Unknown vs Non-Hispanic } \\
\text { mean difference }=-4.71(-13.25,3.84), p=0.09) \text {. }\end{array}$} \\
\hline
\end{tabular}

Table 4

Logistic Regression Model to assess the association between inhalant groups and presence of cough in the past 30 days

\begin{tabular}{|c|c|c|c|c|}
\hline Pairwise Group Comparisons & OR & $95 \% \mathrm{Cl}$ & $\begin{array}{l}\text { Raw } \\
\text { p-value }\end{array}$ & $\begin{array}{l}\text { Adjusted } \\
\text { p-value }\end{array}$ \\
\hline Dual vs Nonsmoker & 1.47 & $(1.06,2.04)$ & 0.019 & 0.038 \\
\hline Dual vs E-cig & 3.03 & $(1.65,5.56)$ & $<0.001$ & $<0.001$ \\
\hline Dual vs Conventional & 1.54 & $(0.96,2.46)$ & 0.073 & 0.088 \\
\hline E-cig vs Nonsmoker & 0.49 & $(0.28,0.86)$ & 0.013 & 0.038 \\
\hline E-cig vs Conventional & 0.51 & $(0.25,1.01)$ & 0.055 & 0.083 \\
\hline Conventional vs Nonsmoker & 0.96 & $(0.61,1.52)$ & 0.855 & 0.855 \\
\hline \multicolumn{5}{|c|}{$\begin{array}{l}\text { Model adjusted for age }(\mathrm{OR}=0.99 \text { per year increase, } 95 \% \mathrm{Cl}:(0.97,1.00), p=0.019) \text { and gender }(\text { Male } \\
\text { vs Female } \mathrm{OR}=1.29,95 \% \mathrm{Cl}:(0.98,1.70), p=0.01), \text { Race }(\text { Asian vs White mean difference }=0.83(0.59 \text {, } \\
\text { 1.17); Other vs White mean difference }=0.96(0.62,1.49), p=0.55) \text {, and Ethnicity (Hispanic vs Non- } \\
\text { Hispanic mean difference }=0.55(0.34,0.89) ; \text { Unknown vs Non-Hispanic mean difference }=0.29(0.09 \text {, } \\
0.87), p=0.07) \text {. }\end{array}$} \\
\hline
\end{tabular}

\section{Dual Users of E-cigarettes and Conventional Tobacco have Greater Drug Use}

Cross-tabulation was used to compare drug use across inhalant use groups. Regardless of gender, more dual users $(42 \%)$ and e-cigarette users $(45 \%)$ reported marijuana use relative to non-smokers/non-vapers $(5 \%)$ and conventional tobacco users $(19 \% ; p<0.001)$ (Fig. 3A). Additionally, more dual users $(10 \%)$ 
reported use of cocaine than non-smokers/non vapers ( $0.4 \%)$, conventional users $(5 \%)$, and e-cigarette users $(0 \% ; p<0.001)$ (Fig. 3B). E-cigarette users $(4 \%)$ and dual users $(4 \%)$ had higher methamphetamine use than conventional tobacco smokers $(2 \%)$ and non-smokers/non-vapers $(0.4 \% ; p=0.007)$. More dual users $(4 \%)$ reported use of $\mathrm{N}, \mathrm{N}$-dimethyltryptamine (DMT) than non-smokers/non vapers $(0.2 \%)$, conventional tobacco smokers (1\%), and e-cigarette users (1\%). Two participants reported heroin/morphine/fentanyl use, and both were dual users. Seven participants reported using prescription tablet opiates, 4 reported using recreational opiates, and 2 reported using PCP, with a majority of these being dual users.

\section{Discussion}

These data demonstrate that dual use of e-cigarettes with conventional tobacco is associated with increased cough as well as increased sleep latency. Historically, conventional tobacco is well known to cause both cough and increased sleep latency $(20,21)$. As dual users have been found to have higher levels of nicotine exposure relative to use of either inhalant alone (22), the increased time to fall asleep may be directly due to the activating effects of nicotine in the central nervous system (CNS). It is also possible that the higher incidence of bothersome cough may itself result in longer sleep latency. More studies are needed to better define the health impacts of e-cigarettes and dual use, and the mechanisms underlying them.

Because impaired sleep or sleep disturbance have been associated with worse outcomes across disease states, determining that the largest group of adult e-cigarette users (dual users) have altered sleep is of particular concern. Studies have found that sleep disruption adversely impacts outcomes in cardiovascular disease, cancer, and infectious disease. Thus, the data presented here suggest that dual users of conventional tobacco products with e-cigarettes may also have poorer outcomes across disease states.

As dual users reported the highest use of drugs such as cocaine and methamphetamine relative to all other groups, the gateway hypothesis may be a possible explanation. Dual use of both e-cigarettes and conventional tobacco may serve as a gateway to additional drug use, as users may have an increased desire to consume other drugs (23). It is possible that dual users believe that other drugs are either less risky or more pleasurable than e-cigarettes and conventional tobacco. Further studies are needed to explain the causal mechanism of dual use of e-cigarettes and conventional tobacco leading to other drug use.

Our study has several limitations. First, we prospectively recruited our cohort through social media platforms such that there is potential participation bias, limiting our conclusions to the population studied. Second, survey research relies on self-report, such that some inaccuracy is likely, but misclassification should be random and bias towards the null hypothesis. Third, the low response percentage from underrepresented minorities including, Alaska Native, Pacific Islander, Middle Eastern, Hispanic, African American and Mixed ethnicities, means that the results of our study may not be 
applicable to these groups. However, while this study has limitations, our findings validate those of our smaller pilot study in 2018, confirming that dual usage affects sleep latency (8).

This work suggests that dual usage of e-cigarettes with conventional tobacco is associated with adverse effects on sleep, including increasing the amount of time it takes to fall asleep. Because dual use was also associated with increased cough, it is possible that cough is the primary contributor to increased sleep latency. Finally, dual use was associated with the highest use of cocaine, marijuana, DMT and opiates across inhalant users. Further studies are needed to determine the mechanisms underlying these findings.

\section{Declarations}

AUTHOR CONTRIBUTIONS: Conception and design of the experiments: LCA, AM, SB, DG, and IA. Acquisition, analysis, and interpretation of data: IA, DG, SP, KP, SP, JP, SN, JO, LM, JMS, XS, SJ, AM and LCA. Manuscript composition: IA, DG, XS, SJ, and LCA. All authors reviewed, contributed to, and approved the manuscript.

FUNDING: This work was supported by grants from the National Institutes of Health NHLBI R01HL147326 (LCA) and the Tobacco-Related Disease Research Program T30IP0965 (LCA).

DISCLAIMERS: None

CONFLICT OF INTEREST STATEMENT: The authors have no conflicts of interest to disclose.

\section{References}

1. Miech R, Johnston L, O'Malley PM, Bachman JG, Patrick ME. Trends in Adolescent Vaping, 20172019. N Engl J Med 2019.

2. CDC. Youth and Tobacco Use. In: Promotion NCfCDPaH, editor. CDC Website: CDC; 2020.

3. Crotty Alexander L, Fuster M, Montgrain P, Malhotra A. The Need for More E-Cigarette Data: A Call to Action. Am J Respir Crit Care Med 2015; 192: 275-276.

4. Bozier J, Chivers EK, Chapman DG, Larcombe AN, Bastian N, Masso-Silva JA, Byun MK, McDonald CF, Alexander Crotty LE, Ween MP. The Evolving Landscape of Electronic Cigarettes: A Systematic Review of Recent Evidence. Chest 2020.

5. Crotty Alexander LE, Drummond CA, Hepokoski M, Mathew D, Moshensky A, Willeford A, Das S, Singh P, Yong Z, Lee JH, Vega K, Du A, Shin J, Javier C, Tian J, Brown JH, Breen EC. Chronic inhalation of ecigarette vapor containing nicotine disrupts airway barrier function and induces systemic inflammation and multiorgan fibrosis in mice. Am J Physiol Regul Integr Comp Physiol 2018; 314 : R834-R847.

6. Alexander LEC, Bellinghausen AL, Eakin MN. What are the mechanisms underlying vaping-induced lung injury? J Clin Invest 2020; 130: 2754-2756. 
7. Crotty Alexander LE, Ware LB, Calfee CS, Callahan SJ, Eissenberg T, Farver C, Goniewicz ML, Jaspers I, Kheradmand F, King TE, Jr., Meyer NJ, Mikheev V, Shields PG, Shihadeh A, Strongin R, Tarran R. NIH Workshop Report: E-cigarette or Vaping Product Use Associated Lung Injury (EVALI): Developing a Research Agenda. Am J Respir Crit Care Med 2020.

8. Boddu SA, Bojanowski CM, Lam MT, Advani IN, Scholten EL, Sun X, Montgrain P, Malhotra A, Jain S, Alexander LEC. Use of Electronic Cigarettes with Conventional Tobacco Is Associated with Decreased Sleep Quality in Women. Am J Respir Crit Care Med 2019; 200: 1431-1434.

9. (US) OoSaH. Women and Smoking: A Report of the Surgeon General. Centers for Disease Control and Prevention (US): Atlanta (GA): CDC; 2001.

10. Advani I, Gunge D, Banks S, Mehta S, Park K, Patel M, Malhotra A, Crotty Alexander LE. Is Increased Sleep Responsible for Reductions in Myocardial Infarction During the COVID-19 Pandemic? Am J Cardiol 2020; 131: 128-130.

11. Buysse DJ, Reynolds CF, 3rd, Monk TH, Berman SR, Kupfer DJ. The Pittsburgh Sleep Quality Index: a new instrument for psychiatric practice and research. Psychiatry Res 1989; 28: 193-213.

12. Dicpinigaitis PV, Lee Chang A, Dicpinigaitis AJ, Negassa A. Effect of e-Cigarette Use on Cough Reflex Sensitivity. Chest 2016; 149: 161-165.

13. King JL, Reboussin BA, Wiseman KD, Ribisl KM, Seidenberg AB, Wagoner KG, Wolfson M, Sutfin EL. Adverse symptoms users attribute to e-cigarettes: Results from a national survey of US adults. Drug Alcohol Depend 2019; 196: 9-13.

14. King JL, Reboussin BA, Merten JW, Wiseman KD, Wagoner KG, Sutfin EL. Negative health symptoms reported by youth e-cigarette users: Results from a national survey of US youth. Addict Behav 2020; 104: 106315.

15. S. A. Boddu ELS, C. M. Bojanowski, I. Advani, S. Nilaad, A. Jahan, Yi Chen, Naa-Oye Bosompra, A. Malhotra, L. E. Crotty Alexander. Investigating the Effects of Different Forms of Tobacco Use on Sleep Quality and Cough: A Matter of Gender? American Thoracic Society International Conference. Dallas, TX; 2019.

16. Birring SS, Prudon B, Carr AJ, Singh SJ, Morgan MD, Pavord ID. Development of a symptom specific health status measure for patients with chronic cough: Leicester Cough Questionnaire (LCQ). Thorax 2003; 58: 339-343.

17. Grant JE, Lust K, Fridberg DJ, King AC, Chamberlain SR. E-cigarette use (vaping) is associated with illicit drug use, mental health problems, and impulsivity in university students. Ann Clin Psychiatry 2019; 31: 27-35.

18. Kinnunen JM, Ollila H, Minkkinen J, Lindfors PL, Timberlake DS, Rimpela AH. Nicotine matters in predicting subsequent smoking after e-cigarette experimentation: A longitudinal study among Finnish adolescents. Drug Alcohol Depend 2019; 201: 182-187.

19. Benjamini Y, Hochberg, Y. . Controlling the false discovery rate: a practical and powerful approach to multiple testing. Journal of the Royal Statistical Society Series B 1995; 57: 289-300. 
20. Hartmann-Boyce J, McRobbie H, Bullen C, Begh R, Stead LF, Hajek P. Electronic cigarettes for smoking cessation. Cochrane Database Syst Rev 2016; 9: CD010216.

21. Bilsky SA FM, Knapp AA, Babson KA, Leen-Feldner EW. The interaction between anxiety sensitivity and cigarette smoking level in relation to sleep onset latency among adolescent cigarette smokers. Journal of Adolescence 2016; 51: 123-132.

22. Berlin I, Nalpas B, Targhetta R, Perney P. Comparison of e-cigarette use characteristics between exclusive e-cigarette users and dual e-cigarette and conventional cigarette users: an on-line survey in France. Addiction 2019; 114: 2247-2251.

23. Chapman S, Bareham D, Maziak W. The Gateway Effect of E-cigarettes: Reflections on Main Criticisms. Nicotine Tob Res 2019; 21: 695-698.

\section{Figures}

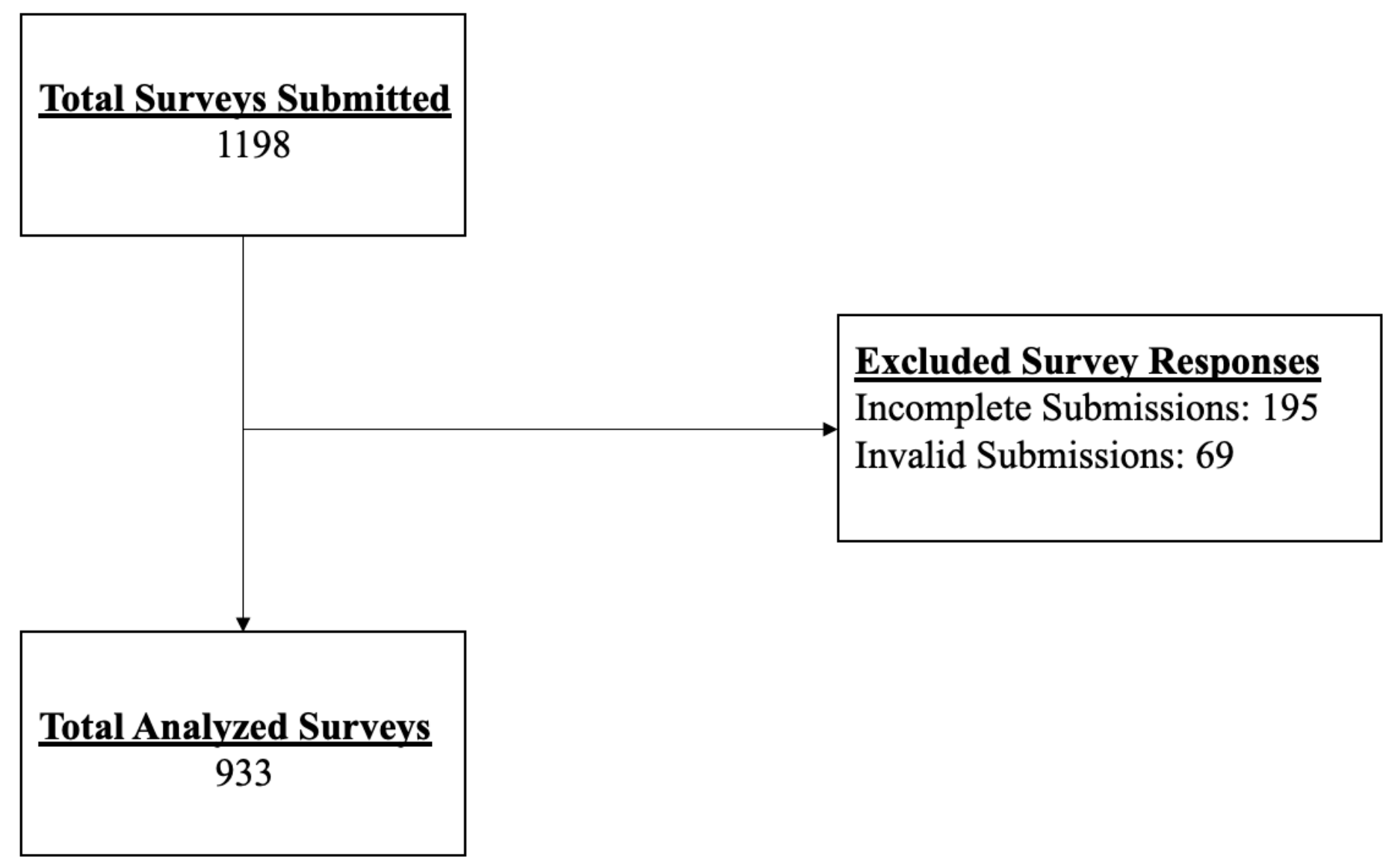

Figure 1

Flow chart of subjects whom participated in the online survey and the surveys excluded for analysis due to incomplete or invalid responses - those with unrelated or uninterpretable responses to the question(s). 


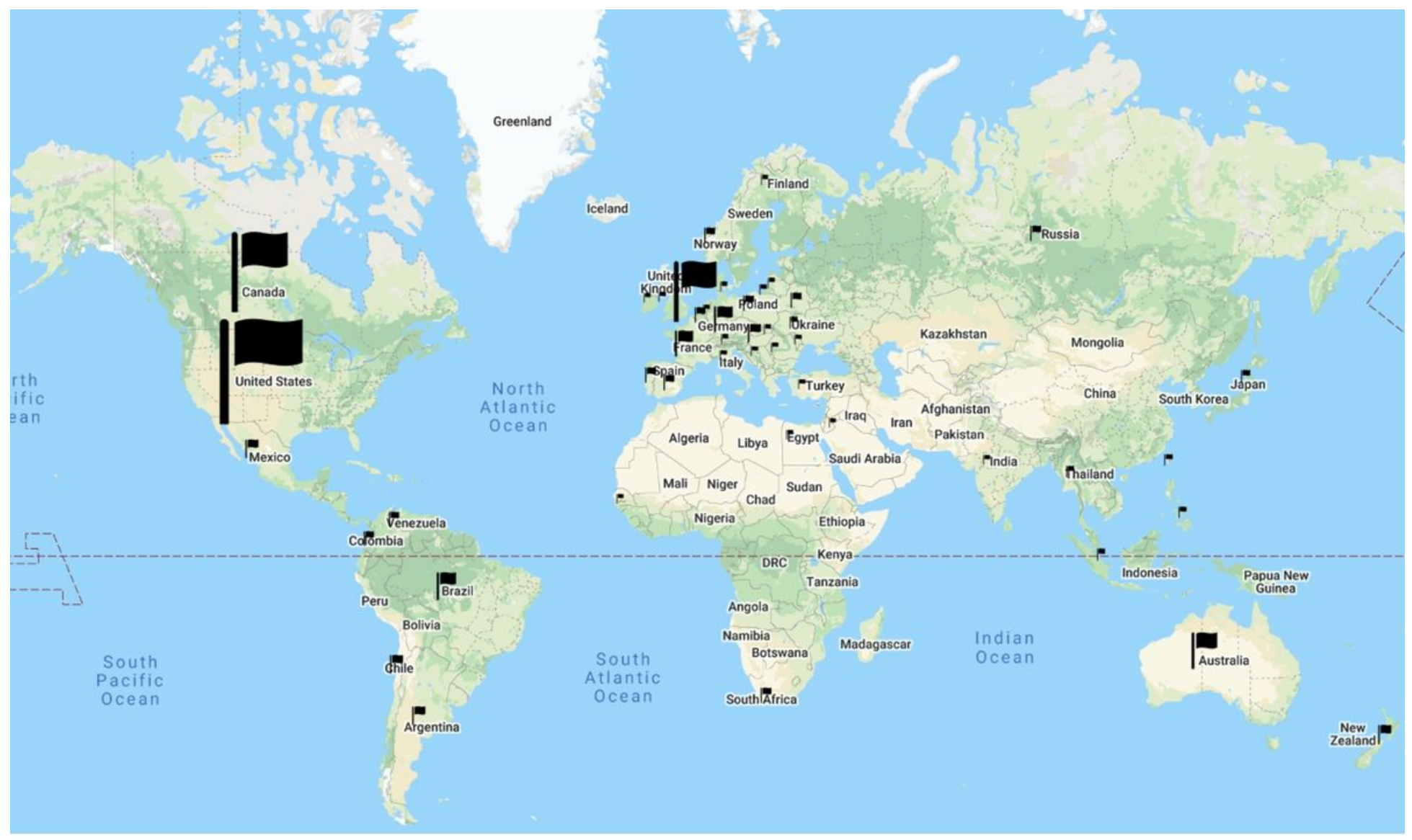

\section{Figure 2}

Responses were collected from 47 countries across 6 continents. Locations of the 1198 survey responders, by IP address. The size of the symbol is directly proportional to the number of responses received from the region. For reference, the number of survey responses from US $=897$, Brazil $=9$, United Kingdom $=175$, Egypt $=1$, New Zealand $=2$. Note: The designations employed and the presentation of the material on this map do not imply the expression of any opinion whatsoever on the part of Research Square concerning the legal status of any country, territory, city or area or of its authorities, or concerning the delimitation of its frontiers or boundaries. This map has been provided by the authors. 

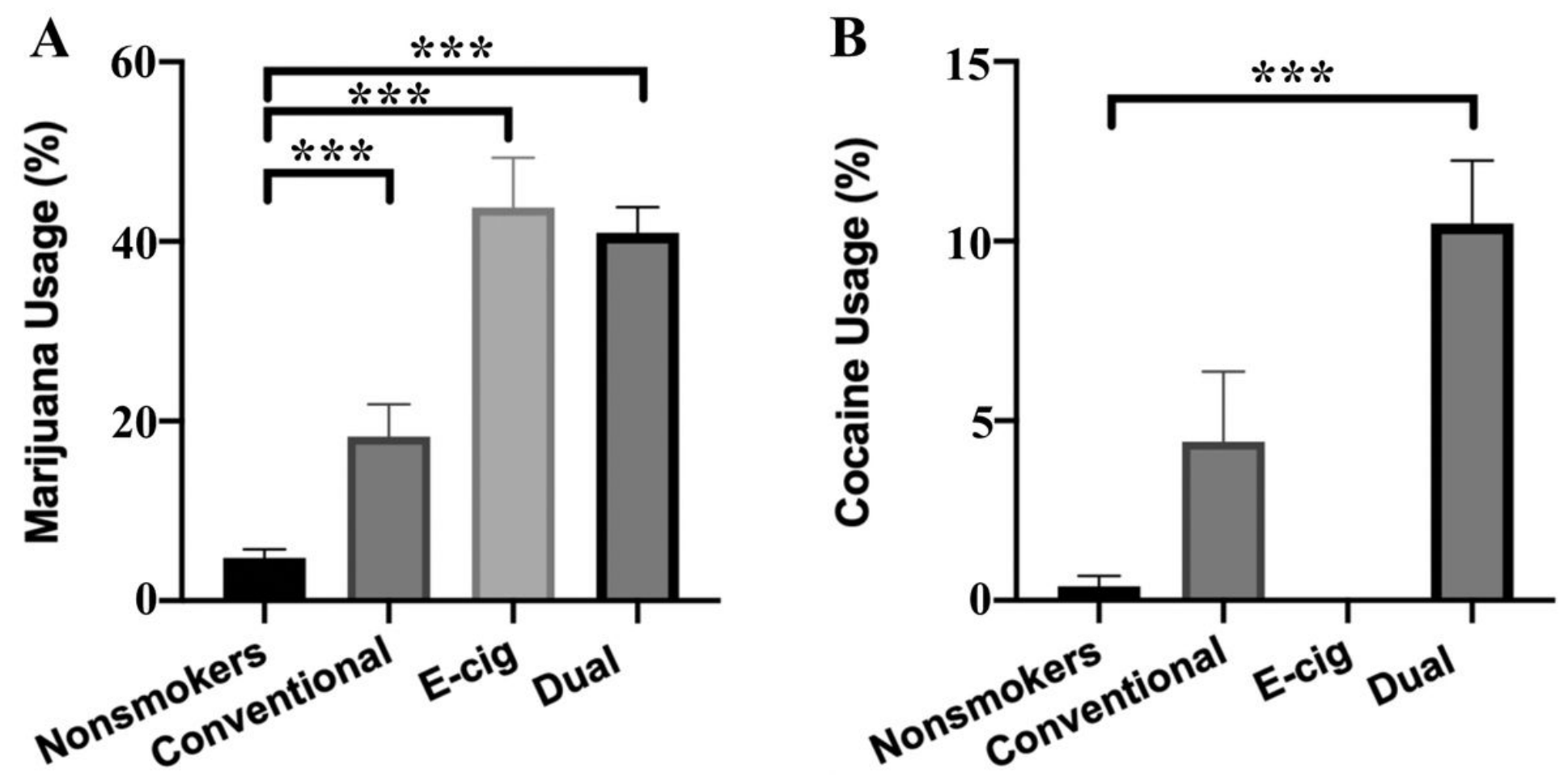

Figure 3

Dual users have high rates of other drug use, including marijuana. A. Marijuana Usage across Inhalant groups. Dual users reported more marijuana usage when compared to non-smokers. B. Cocaine usage across Inhalant groups. Dual users reported higher cocaine usage than non-smokers and e-cigarette users. ${ }^{\star * \star} p<0.001$ 